\title{
Ser Auxiliar de enfermagem: um olhar da psicodinâmica do trabalho
}

\author{
LAERTE SZneLwar \\ Universidade de São Paulo, Escola Politécnica, Departamento de Engenharia de Produção \\ E-mail: laertesz@usp.br \\ SEIJI UCHIDA \\ Escola de Administração de Empresa de São Paulo - Fundação Getúlio Vargas - FSJ \\ E-mail: suchida@fgvsp.br
}

\begin{abstract}
Resumo
No presente artigo, são apresentados os resultados de uma ação desenvolvida sob o ponto de vista da psicodinâmica do trabalho com auxiliares de enfermagem em um hospital universitário. Através da criação de um grupo de expressão, foram abordadas questões ligadas às vivências e experiências destes trabalhadores. Os resultados evidenciam uma série de questões relacionadas à questão do sofrimento no trabalho, principalmente no que tange à maneira como este é organizado e às tarefas concebidas. Apesar da predominância no discurso dos trabalhadores do tema do sofrimento, questões relacionadas com o prazer no trabalho, ligadas à constituição do saber, da identificação com o trabalho, da importância do que fazem, pois seriam uma espécie de guardiães, o último elo na cadeia de assistência ao paciente, também foram evidenciadas.
\end{abstract}

Palavras-chave

Auxiliares de enfermagem, trabalho em hospitais, psicodinâmica do trabalho, sofrimento, prazer, identidade

\section{To be nurse auxiliary: the point of view of work psychodynamics}

\begin{abstract}
This paper presents the results of a study made with nurse auxiliaries in a hospital using the work psychodynamics approach. An expression group was created to discuss workers' experiences about their work. The results put in evidence questions linked to suffering due to work organisation and task content. Otherwise, even if suffering was the main theme, aspects related to pleasure in performing their work, due to the constitution of knowledge, identification with the work, to the consciousness of the importance of their acts were also discussed. Somehow they represent themselves as guardians, the last link in the chain of assistance.
\end{abstract}

\section{Key words}

Nursing, work in hospitals, work psychodynamics, suffering, pleasure, identity. 


\section{INTRODUC̣̃̃O}

O presente artigo é resultado de uma ação baseada em preceitos da psicodinâmica do trabalho, desenvolvida num hospital universitário de uma cidade de médio porte situada em um dos estados do sul do Brasil. Este tipo de ação é baseado na premissa de que, para transformar o trabalho, é importante que seja realizada uma atividade de elaboração coletiva, através da criação de um espaço público dentro das organizações, onde seja possível para os integrantes se expressarem a partir do vivido. A tensão criada entre as expectativas e sonhos dos trabalhadores e a organização do trabalho e o conteúdo das tarefas pode vir a ser a fonte do sofrimento no trabalho. Sofrimento este que pode desencadear ações criativas, mudanças, melhorias, como uma espécie de efeito catalisador. Entretanto, em muitas situações de trabalho, como no caso deste estudo, a maneira como o trabalho é organizado e são definidas as tarefas, cria-se uma verdadeira barreira a este processo. O trabalho realizado não é reconhecido, o sofrimento não é reconhecido, a fala das pessoas não é estimulada, pelo contrário, é freqüentemente combatida. O cenário para que este sofrimento se torne patogênico está então criado. No caso deste trabalho, a demanda partiu da direção de enfermagem do hospital. Sua preocupação era a de entender o impacto de mudanças institucionais instituídas recentemente e abrir um espaço para tomar conhecimento dos possíveis efeitos negativos e permitir uma elaboração que ajudasse a transformar a situação.

\section{Aspectos conceituais}

Em seu percurso teórico, Dejours (2000) situa-se inicialmente dentro de uma tradição francesa conhecida como psicopatologia do trabalho. Este foi o nome dado pelos psiquiatras sociais Sivadon, Guillant e Bègoin (BILLIARD, 1996) a uma disciplina iniciada nos anos 1950 e 1960. Esta escola, a exemplo das teorias formuladas pela medicina do trabalho, tinha como finalidade buscar a relação entre determinadas maneiras de organizar, as condições e o conteúdo de trabalho com adoecimento psíquico. Dejours, influenciado por esta corrente, procura compreender o sofrimento psíquico no trabalho, e todo o seu esforço passa a ser estabelecer relações entre os constrangimentos organizacionais e possíveis descompensações psicológicas dos indivíduos.

Neste momento, compreendia a organização do trabalho, conceito central dentro de sua obra, "como um dado préexistente ao encontro entre o homem e o trabalho, como um conjunto de constrangimentos massivos, monolíticos, inabaláveis, até inexoráveis, tendo o peso e a rigidez da matéria mineral" (DEJOURS, 2000, p.205). Esta realidade produziria um impacto violento e opressivo sobre o trabalhador.
Nesse sentido, dadas estas condições, ele esperava encontrar afecções psicopatológicas como efeito resultante da confrontação dos trabalhadores com a organização do trabalho. Contudo, como psicanalista, o autor intuía que os indivíduos não eram passivos diante das injunções organizacionais: estes buscariam se proteger dos efeitos nocivos sobre a psique e, conseqüentemente, evitar cair no adoecimento mental. Sofriam, mas criavam estratégias defensivas individuais ou coletivas, que pudessem preservá-los do sofrimento. Só que, na concepção dominante na maneira de organizar o trabalho, os indivíduos tinham um espaço limitado para se desenvolver: restava somente o espaço da invenção de modalidades de adaptação às situações concretas. Por mais engenhosa e inteligente que a invenção fosse, não evitava e nem afastava o risco da alienação mental (DEJOURS, 2000, p. 206).

Com o desenvolvimento dos estudos em situações concretas de trabalho em empresas e instituições feitos por ele e sua equipe, foi sendo constatado que, apesar da violenta deterioração de muitas situações do trabalho, freqüentemente os trabalhadores conseguiam evitar o adoecimento. Destaca este "estranho silêncio", ou seja, não encontrava os "ruídos" da loucura e da afecção psicopatológica. Em seu lugar, observava um estado de "normalidade".

Este ponto surge agora como o enigma central de investigação e análise: o foco de pesquisa se desloca para este novo fenômeno. Aquilo que, aparentemente, é natural e óbvio para as pessoas passa a ser um problema a ser explicado, um enigma. Ao passar da psicopatologia para a normalidade, Dejours passa a chamar o seu novo campo de pesquisa e as teorias que passa a formular de psicodinâmica do trabalho ou Análise Psicodinâmica do Trabalho.

Deve-se alertar que esta "normalidade" é fruto de um equilíbrio instável, essencialmente precário, entre o sofrimento psíquico e as defesas utilizadas contra ele. Nesse sentido, esta situação mascara um estado de sofrimento patogênico. Mas, ter a normalidade enquanto objeto de estudo abre um enorme campo que vai incluir o prazer, o trabalho, a identidade, a dinâmica interna da situação do trabalho, a questão do reconhecimento (de beleza e utilidade), criatividade, eficácia, e assim por diante.

No nosso entender, o que o autor defende a partir deste momento é que não se deve confundir estado de normalidade com estado saudável. Se, de um lado, a normalidade pode ser o signo de equilíbrio saudável entre as pessoas, pode, de outro, ser o do mascaramento de um sofrimento atroz, ou seja, o estabelecimento de um precário equilíbrio entre as forças desestabilizadoras dos sujeitos e o esforço destes e dos grupos no sentido de se manterem produtivos e atuantes à custa de muito sofrimento.

Este sofrimento não se manifesta na forma de afecção psicopatológica porque os sujeitos buscam ativamente se 
proteger e defender. Lançam mão ou de mecanismos de defesa, quando trabalham sós e isolados, ou de estratégias de defesa coletiva, quando o trabalho é em grupo. A patologia surge quando se rompe o equilíbrio e o sofrimento não é mais contornável. Em outros termos, esta surge quando os recursos intelectuais e psicoafetivos dos trabalhadores requisitados para dar conta da tarefa e das demandas impostas pela organização não são suficientes e fica patente que nada podem fazer para transformar o trabalho.

Note-se que em muitas situações do trabalho vários sinais de sofrimento serão considerados como "normais" pelos próprios indivíduos: cefaléias, insônias, alergias, queda de cabelos, irritação contínua, etc. No máximo dirão que vivem "estressados" e que isto se deve às pressões naturais da situação do trabalho.

Um outro aspecto importante deste processo de desenvolvimento teórico-conceitual foi o encontro com a ergonomia francesa. A distinção realizada entre trabalho prescrito e trabalho real (GUÉRIN 2001), foi uma contribuição importante para se questionar a dimensão monolítica da organização do trabalho. Os trabalhadores seguem, dentro do possível, prescrições e normas de procedimentos para executar as suas tarefas. Freqüentemente uma parte da realidade se destaca na forma de resistência às prescrições, ou seja, trata-se sempre de uma situação desconhecida, imprevista, imprevisível que as coloca em cheque. O trabalhador neste momento se encontra diante de um dilema: de um lado, a organização "espera" que ele cumpra o previsto e de outro, se seguir a prescrição não dará conta da nova situação. A saída é lançar mão da trapaçal, ou seja, "trapacear as regras" para desenvolver o trabalho. Abre-se assim o campo para pensar a possibilidade do indivíduo agir sobre a situação do trabalho. Ele não é somente um sujeito que deve se adaptar à organização e às condições do trabalho. Mas, deve recriar a tarefa, que implica a possibilidade da transformação do trabalho, dentro de determinados limites. O resultado deste processo onde são buscadas novas soluções a despeito das prescrições é nomeado de trabalho real. Só que isto não ocorre sem riscos. O fato de transgredir as regras, e o sujeito o faz conscientemente, suscita necessariamente preocupação e angústia: ele não tem certeza da justeza da solução.

É necessário submeter ao julgamento dos pares a solução dada. Segundo Dejours, é o mais temível julgamento a que se submete, pois são os que verdadeiramente têm condições, experiências, conhecimentos, habilidades e competências para julgar o que foi feito. Caso o "veredicto" seja favorável, o trabalhador recebe o reconhecimento pela beleza da solu- ção, e esta pode ser adotada pelo grupo, podendo fazer parte do que Clot $(1995,1999)$ considera como fazendo parte do gênero profissional. Do contrário, o indivíduo que não recebe um julgamento favorável irá sofrer pela transgressão e a não solução do problema. Pode ser levado, no limite, a viver intensamente um sofrimento que pode se tornar patogênico, com consequiências graves para a sua saúde.

Esta mesma solução pode também ser reconhecida pela chefia e, quando estiverem envolvidos, pelos clientes. Neste caso trata-se do reconhecimento de utilidade. Entretanto, na maioria das vezes as mudanças nas regras do trabalhar se dão sob silêncio, ficam invisíveis. Em certas situações podem ser estabelecidos acordos tácitos. A hierarquia imediata sabe que é impossível cumprir o prescrito, mas também não tem como modificá-lo. Estes acordos são frágeis e podem ser rompidos pelos mais variados motivos.

Gostaríamos também de ressaltar que em muitos destes processos de trabalho pode ser evidenciado o que Dejours $(1993,1995)$ chama inteligência astuciosa. É uma inteligência prática "essencialmente engajada nas atividades técnicas, em particular nas atividades de fabricação (poïèsis)". Caracteriza-se por um certo número de traços: "é mobilizada frente a situações inéditas, ao imprevisto, frente a situações móveis e cambiantes; ilustra-se particularmente na atividade do caçador, na arte do navegador ou do médico; sua competência é a astúcia; ela está fundamentalmente enraizada no engajamento do corpo, poupa esforços e privilegia a habilidade em detrimento do emprego da força; é inventiva e criativa" (1995, p. 46).

\section{A tensão criada entre as expectativas e A sonhos dos trabalhadores e a organização do trabalho e o conteúdo das tarefas pode} vir a ser a fonte do sofrimento no trabalho.

Um outro aspecto importante está ligado à questão do corpo, a psique existe corporificada, não existe como uma entidade abstrata, baseada no que poderíamos definir como domínio do afetivo e da inteligência. A psique, assim como a cognição, estão enraizadas no corpo: "esta dimensão corporal da inteligência prática é importante a ser considerada na medida em que implica um funcionamento que se distingue fundamentalmente de um raciocínio lógico. É a desestabilização do corpo em sua relação à situação que mobiliza, inicia e acompanha o jogo desta inteligência prática” (1995, p. 50). Vai ser através da detecção e tratamento dos dados relativos à operação que um trabalhador irá esboçar rapidamente um diagnóstico ou uma medida corretiva. 
Podemos observar, através do que foi exposto até o presente momento, como os novos elementos abertos pela normalidade, vão sendo articulados e como novos temas vão surgindo. Por exemplo, para a prática da trapaça são necessárias criatividade e inteligência, mas não basta ser criativo e inteligente, é necessário que a solução seja eficaz. Ora, como desenvolvemos anteriormente, da mesma forma como a trapaça é julgada pelos pares, a criatividade, inteligência e a eficácia da solução também estão sendo julgadas ao mesmo tempo. Isto permite transformar o sofrimento potencialmente patogênico em sofrimento criativo. Isto pode produzir satisfação no trabalho, ou seja, há vivência de um intenso prazer quanto maior for o desafio enfrentado. $\mathrm{O}$ processo criativo e seu reconhecimento levam-nos a discutir também um outro conceito fundamental para a promoção da saúde do trabalhador: a identidade.

Identidade é o conceito que permite entender a nossa necessidade de sermos únicos, singulares, diferentes do outro. É distinto do conceito de personalidade. Como recorda Dejours (1995),

\begin{abstract}
“(...) uma parte importante da tradição psicanalítica confere um lugar essencial à análise da personalidade ou do caráter, isto é, às invariantes que resultam da sedimentação do drama da infância e conferem à pessoa uma estabilidade que tem freqüentemente sido considerada como uma estrutura. Portanto, a personalidade, o caráter ou a estrutura não afastam os riscos da crise psíquica e da descompensação. $\mathrm{O}$ recurso à noção de identidade permite precisamente problematizar esta tensão entre o que vem do passado que confere a estabilidade e o que na atualidade, cria o risco de desestabilizar o sujeito ou de provocar as crises de mudança. A identidade nesta perspectiva conserva sempre uma certa precariedade e jamais é definitivamente adquirida" (p. 189)
\end{abstract}

A identidade é algo que se constrói na relação com o outro (VÉZINA, 2000), ou seja, passa pelo julgamento e reconhecimento do outro. Isto significa que na situação do trabalho, passa inicialmente pelo fazer. É a ação que irá primeiramente ser julgada. Mas esta é fruto da experiência, desenvolvimento das habilidades, competências e saberes práticos e teóricos. A ação atual é fruto de um longo percurso de vida do sujeito, logo, quando o seu fazer é julgado, o seu ser indiretamente também o é. Por isso, o reconhecimento (de beleza e de utilidade) terá uma grande repercussão no processo de identificação com o trabalho, conseqüentemente de fortalecimento da singularidade do sujeito, da sua identidade.

Mas o fazer requer visibilidade e esta pressupõe risco subjetivo. Submeter-se ao julgamento do outro significa correr este risco, e este só pode ser assumido quando existe uma relação interpessoal de confiança. Esta só ocorre quando se constrói um clima de respeito e justiça com relação às ações das pessoas. Se existe transparência no julgamento do fazer e que não seja distorcido por ambições outras que contaminem este julgamento, tais como desejo de poder e dominação, pode-se criar um clima de cooperação. Por outro lado, a invisibilidade impossibilita o reconhecimento. $\mathrm{O}$ sujeito corre um outro tipo de risco, o do anonimato e perda de identidade, que no limite ameaça sua saúde psíquica.

A construção da confiança, essencial para a saúde, depende também da criação de um coletivo de trabalho que, segundo Dejours (1999) não é apenas um grupo, mas o resultado da construção comum de regras e do ofício. Faz parte deste processo, a atividade deôntica, a atividade de construir acordos, normas e valores que se estabilizam sob a forma de regras. Logo, a construção de um espaço para a livre circulação da palavra coletiva é essencial para a saúde que passa pela construção de uma identidade sólida que requer relações de confiança que só poderão ser produzidas quando há normas e valores éticos que norteiem as relações dentro de uma determinada organização.

Neste momento é fundamental distinguir a experiência coletiva da experiência compartilhada. Não existe uma experiência coletiva vivida por todos igualmente. O sofrimento, por exemplo, não é coletivo, ele é individual. A experiência que os trabalhadores têm da mesma situação que produz sofrimento não é a mesma para cada um deles, não é comum a eles. O que é comum é o fato de muitos dentre eles sofrerem. Podemos compartilhar então como cada um sofre, ou seja, sua inteligibilidade, o seu sentido. No coletivo, o que se constrói é o sentido comum dos sofrimentos vividos. Vai ser através dos atos de linguagem ou, como diria Habermas (1987), ações comunicativas que podemos compartilhar o sofrimento. Para que isso ocorra é necessária a construção de um espaço comum, público, ou no dizer de Arendt (1981) esfera pública, de livre circulação da palavra para que se possa criar uma linguagem comum que leve a uma nova inteligibilidade, uma nova interpretação e um novo sentido ao trabalho.

As regras do métier (CRU, 1987) são um elo intermediário nesta construção. É uma condição necessária, mas não suficiente entre o reconhecimento de pares e a negociação da organização real do trabalho. As regras são atravessadas pelas relações sociais do trabalho, fundamentais para a criação do espaço de cooperação, pois este repousa sobre a construção e transformação das regras de trabalho. E isto somente irá ocorrer com um espaço que respeite as diferentes manifestações e discussões entre os sujeitos e que permi- 
tam, através dos atos de linguagem, a criação das normas que vão reger as relações interpessoais.

Com relação ao método proposto por Dejours (2000), gostaríamos de ressaltar alguns aspectos. A discussão sobre as possibilidades de ação em psicodinâmica do trabalho em nosso meio é muito recente, uma vez que a prática ainda é incipiente e as representações que existem quanto ao que de fato significa uma intervenção neste campo podem variar substancialmente. A questão principal seria, o que se espera deste tipo de intervenção? A criação de um "espaço público", dentro do ambiente de uma empresa, ou entre profissionais de uma determinada categoria abre a perspectiva de trocas e de questionamentos que não se realizavam antes. A perspectiva de se colocar "em público" o ponto de vista subjetivo de um determinado coletivo exibe problemas e contradições existentes nas organizações, que podem ser inclusive geradores de sofrimento. Estas questões devem ser situadas. Discutir a prática em psicodinâmica do trabalho, em uma determinada situação deve considerar a história e a cultura locais. A prática de uma certa democracia dentro das empresas, no Brasil, é pouco difundida, uma vez que ainda há poucos exemplos em que os trabalhadores se organizam no interior destas. Há poucos comitês de empresa onde há representação sindical, e os próprios sindicatos não têm representação formal por empresa, estes se organizam fora delas. Portanto, podemos considerar que a proposição de uma ação em psicodinâmica do trabalho, com a criação de grupos de trabalhadores para se expressar dentro das empresas, pode ser considerada como uma situação nova em que, muito provavelmente, será a primeira vez em que é possível se expressar efetivamente dentro do coletivo de trabalho.

\section{Trabalhar como auxiliar de} enfermagem ${ }^{2}$ em hospitais

O objetivo deste trabalho não é o de analisar em profundidade o conteúdo e a organização do trabalho de auxiliares de enfermagem em hospitais, mas sim discutir sobre a experiência vivida por estas pessoas em uma determinada situação de trabalho. Portanto, os resultados devem ser analisados em sua singularidade, como fruto das discussões de um determinado coletivo, eles são localizados no tempo e no espaço. Qualquer possibilidade de generalização ficaria por conta de novos estudos. Nesse sentido, o importante é caracterizar o cenário onde estas atividades profissionais são exercidas.
A existência do auxiliar de enfermagem é explicada historicamente pela necessidade de preencher um vazio no atendimento à saúde. Apesar de na época já existir como profissão e haver reconhecimento social, a enfermagem de nível superior não era exercida por uma quantidade suficiente de pessoas que pudessem abarcar todas as tarefas necessárias para o cuidado dos pacientes, principalmente os internados. Na prática, já havia pessoas leigas trabalhando em hospitais nas tarefas de auxílio, mas estas não eram consideradas como profissionais da saúde. Foram criados então cursos técnicos para a capacitação destas pessoas, que passariam a ter um estatuto de profissional de nível não universitário.

\section{$\Lambda$ pesar da violenta deterioração de muitas situações do trabalho, freqüentemente os trabalhadores conseguiam evitar o adoecimento Deve-se alertar que esta "normalidade" é fruto de um equilíbrio instável, essencialmente precário, entre o sofrimento psíquico e as defesas utilizadas contra ele.}

O auxiliar de enfermagem tem a prerrogativa de atuar na grande maioria dos procedimentos técnicos de enfermagem sob a supervisão de profissional de nível superior. Atualmente, apesar das diferenças significativas existentes nos hospitais, o pessoal de enfermagem com nível superior trabalha em tarefas técnicas e gerenciais, chefiando grupos de auxiliares e, mais recentemente, de técnicos de enfermagem, sendo que o técnico tem um nível maior de escolaridade e de especialização que o auxiliar. Já o cargo de atendente de enfermagem, para o qual o nível de escolaridade exigido é baixo, está em vias de desaparecimento em nosso país.

Há diferenças significativas determinadas pela região do país, pela qualidade dos hospitais e pelas características da rede de assistência à saúde. No caso dos auxiliares de enfermagem, estes desenvolvem as mais diferentes atividades, o trabalho que lhes é prescrito é vago e amplo, na medida em que engloba desde ações com grau relativamente alto de complexidade técnica até ações consideradas pela instituição como tecnicamente mais simples, como os cuidados com a higiene dos pacientes, entre outros. Na prática, fica muito difícil separar a tarefa por categorias, uma vez que o atendimento ao paciente envolve todas as ações necessárias e que, muitas vezes, ocorrem simultaneamente. Segundo Molinier (1995), a relação de cuidado não é sim- 
plesmente algo que se justapõe à técnica, como um conforto suplementar ou um prêmio de humanidade, tanto o cuidado como a técnica são indissociáveis.

Uma outra característica do trabalho hospitalar é a existência de eventos de toda natureza. As panes, a falta de material, a ausência de um colega, a evolução repentina do estado de saúde de um paciente, se sobrepõem ao procedimento e ao planejamento. Como descrito por Tonneau et al. (1996), aquela atividade pode ser interrompida naquele momento, mas como consequiência, todo o planejamento das ações da jornada fica comprometido. Cabe aos profissionais de enfermagem, fazer a gestão desta variabilidade e garantir o cumprimento dos cuidados.

No que tange às relações hierárquicas em um hospital, apesar da organização prescrita do trabalho ser clara, a realidade é bem mais complexa e há ambigüidades evidentes. No caso de auxiliares há uma linha direta onde a chefia é exercida por profissional de enfermagem. Entretanto, a relação com outros profissionais da saúde, principalmente com os médicos, é ambígua. No caso específico do hospital onde foi realizado o trabalho, há outras características importantes. Trata-se de um hospital geral e de ensino. Além de profissionais de diferentes áreas da saúde há também estudantes de várias áreas, tais como medicina, fisioterapia, terapia ocupacional, psicologia e enfermagem. Dessa forma, apesar de não haver reconhecimento explícito, eles exercem, de maneira informal, funções que se aproximam da prática do ensino e da supervisão de estagiários.

\section{Metodologia utilizada}

O propósito agora é o de apresentar e refletir criticamente o método usado nesta pesquisa com um grupo de auxiliares de enfermagem ${ }^{3}$ no hospital citado. Procuraremos mostrar, baseados na metodologia proposta por Dejours (2000), como foi o processo desenvolvido, ou seja, caracterizando e refletindo sobre a demanda, o contrato, os encontros realizados e o final da intervenção.

Inicialmente falaremos da demanda. É essencial prestar atenção não só com relação a quem pede, mas ao modo como esta ocorre. Diversamente do que propõe Dejours "uma solicitação só pode ser considerada se for proveniente dos próprios trabalhadores" -, no presente caso o contato para a realização do trabalho foi feito pela direção do hospital, a partir de questões colocadas pela direção da enfermagem, como uma insatisfação crescente expressa em conflitos e uma elevada taxa de absenteísmo. É importante ressaltar também que houve desde o início, por parte da direção, uma certa ambigüidade quanto aos objetivos, uma vez que ficou patente que ela tinha receio quanto aos efeitos institucionais deste tipo de trabalho, uma vez que estaria sendo aberto um canal de comunicação sem que fosse garantido o controle sobre os resultados. Apesar de ter havido várias discussões sobre o que seria este tipo de trabalho, foram explicitadas as diferentes etapas (trabalho da demanda, constituição de grupos homogêneos voluntários, realização de reuniões com a presença apenas dos grupos e dos pesquisadores, redação de um documento, discussão e validação do documento, entrega do documento para os solicitantes - empresa e participantes do grupo), podemos afirmar que ainda havia lacunas substanciais. Apesar de parte da direção do hospital querer conhecer mais profundamente as questões que permeavam o trabalho de auxiliares de enfermagem, havia um receio muito grande com relação aos resultados. Tanto é que a intervenção foi financiada e anunciada pelo hospital como um curso e não como uma ação em psicodinâmica do trabalho.

Temos consciência de que, neste início, o interesse dos funcionários foi mediado pela direção. Por exemplo, na proposta que foi enviada para a direção, foi colocado que a constituição dos grupos deveria ser feita através da livre adesão dos trabalhadores. O fato é que houve três tipos de critérios para a escolha dos participantes: os voluntários na ausência de outros candidatos, os designados pela chefia e os escolhidos democraticamente pelos grupos de trabalho de diversas clínicas do hospital.

\section{Os encontros}

No primeiro encontro os objetivos do trabalho foram explicados e as regras de funcionamento do grupo explicitadas e negociadas. Destacamos:

- A criação de um espaço público para que houvesse a livre circulação de palavras.

- A garantia de sigilo total com relação às falas.

- Ficou estabelecido o papel dos pesquisadores / facilitadores; durante os encontros eles deveriam ter um papel "de escuta", evitando um papel diretivo nas discussões, e produzir um documento parcial a ser apresentado no encontro seguinte que retratasse da forma mais fiel possível o discurso coletivo.

- A produção de um documento final, fruto das discussões e que deveria passar por um processo de validação final pelo grupo.

- O documento seria entregue aos participantes do grupo, à direção do hospital e seria objeto de publicações futuras.

- Ficou também explícito que não havia garantias com relação aos desdobramentos do trabalho, não havia garantias por parte do hospital de que haveria mudanças objetivas na organização e no conteúdo do trabalho deles.

- Que os objetivos do grupo não eram terapêuticos.

- Os resultados seriam o retrato o mais fiel possível do que aquele coletivo criou como discurso sobre como o trabalho era vivido por eles.

Durante a sessão de validação do documento final, procurou-se trabalhar as dúvidas quanto à fidelidade do texto 
em relação ao exposto durante os vários encontros. Surgiram também receios e fantasias persecutórias quanto ao impacto que este causaria na hora de sua divulgação. Houve dúvidas quanto à justeza das colocações feitas principalmente em relação à direção e aos outros colegas e profissionais. Discutiu-se qual uso do documento poderia ser feito. Chegou-se à conclusão de que ali estava retratada de forma mais fiel e clara possível a vivência deles no dia a dia do seu trabalho, e que através de uma relação intersubjetiva foi possível construir um relato que ultrapassava o individual, pois retratava o resultado de um trabalho coletivo, no espaço criado durante as sessões. Portanto, o documento seria fruto de uma criação coletiva, onde cada um se identificava de maneira diferenciada.

Ao todo foram 15 horas de trabalho de grupo, 5 encontros de 3 horas. O grupo foi composto por 15 pessoas, das quais, 14 eram mulheres e um homem. A forte presença feminina retrata a realidade, uma vez que mais de 90\% da população de auxiliares de enfermagem do hospital é composto por mulheres. Os homens trabalham como auxiliares, exercendo principalmente atividades onde é exigida mais a força física. Com relação à idade e ao tempo de trabalho na profissão e no hospital, tratava-se de uma população diversificada, onde a maioria tinha mais de 10 anos de profissão e com idades acima dos 30 anos.

\section{Apresentação dos Resultados}

A auxiliar de enfermagem vai adquirindo experiência e vai constituindo o que Dejours (1993) chama de sabedoria prática. Tendo como base aquilo que aprendeu nos cursos, no contato diuturno com pacientes e na observação da prática do trabalho das enfermeiras e médicos, assim como de outros profissionais da saúde, ela vai incorporando experiências e reforçando a "inteligência astuciosa" que lhes permite trabalhar e exercer suas funções a contento.

A fronteira que separa, o seu trabalho daquele que seria o das enfermeiras é tênue. Elas fariam "tudo" aquilo que as enfermeiras fazem, mas isso não é sabido, o reconhecimento dos outros profissionais, principalmente o dos médicos, não é dirigido a elas.

Há questões levantadas sobre a confiabilidade do siste$\mathrm{ma}$, inclusive quando percebem falhas cometidas durante o processo de tratamento. Neste caso a falta de integração nas equipes de saúde e a pobreza do diálogo ficam patentes. O exemplo a seguir ilustra um caso destes:

“...quando o paciente não está bem, a gente sabe. Teve o caso de uma criança. O plantonista veio ver várias vezes, não tomava as providências necessárias. Eu pensava se não tomar cuidado, vai a óbito. Cheguei a chorar por falha médica”.
Este "olhar" adquirido com a experiência, define uma outra postura frente às ações de saúde. Elas se sentem em constante atividade de vigilância. Os pacientes devem ser protegidos, pois elas seriam o último elo de uma cadeia de cuidados e assistência. Caso algum erro a montante seja cometido, devem ser elas que devem barrá-lo. Para elas é preciso ter certeza que o procedimento clínico está correto, que não houve erro, elas aprendem inclusive a interpretar uma prescrição, com relação à dosagem e mesmo com relação ao tipo de medicamento.

Com sua experiência chegam a ensinar os estudantes de medicina em alguns procedimentos, elas têm prática suficiente para mostrar como se faz, mas isto se passa discretamente, uma vez que não há reconhecimento do seu saber:

"O aluno de medicina solicita ajuda, eles têm conhecimento, mas não tem prática. Já ensinei a aplicar o soro e ele ficava perguntando para mim como é que fazia."

\section{A inteligência astuciosa. Uma inteligência prática "essencialmente engajada nas atividades técnicas, em particular nas atividades de fabricação. (poïèsis)}

Outra vertente deste trabalho que fica completamente invisível é o apoio psicológico que a auxiliar presta aos pacientes e familiares. Em várias situações elas acabam informando a respeito do que sabem sobre os pacientes, mesmo que isto não faça parte dos procedimentos no escopo da sua tarefa.

Não há reconhecimento do seu saber prático, de sua capacidade de avaliar o estado do paciente. As auxiliares se sentem impotentes por nada poderem fazer e de se valer de algum médico que legitime o seu "diagnóstico" para amenizar a angústia de sua "desqualificação" diante do saber médico. É comum, ao oferecerem alguma informação de cunho mais técnico receberem comentários com certa dose de ironia: "como você sabe?".

Outra característica da organização do trabalho no hospital é o constrangimento de tempo, tudo é urgente para quem demanda atenção. Entretanto, o profissional auxiliar precisa fazer uma triagem para conseguir atuar. Mas como definir o que é mais urgente se, em princípio não é de sua alçada fazer diagnóstico clínico?

No momento da pesquisa, o hospital tinha passado por um processo de diminuição do pessoal e isto se tornou uma fonte de sofrimento suplementar. Percebiam que por mais que se desdobrassem, lutavam contra o tempo para dar conta de suas tarefas. Dentre as falas do grupo ficavam 
evidentes questões como a falta de tempo para fazer tudo o que é previsto. Os problemas oriundos da diminuição do número de funcionários, ausência de médicos em alguns momentos de morte em que elas achavam que algo poderia ter sido feito, o tempo gasto quando de um procedimento mais complicado, como a punção de uma veia de uma criança, e a simultaneidade de chamadas urgentes de pacientes compõem este cenário.

se irritarem com as cobranças dos pacientes, acreditam que estes não devem ter paciência, o problema deles é serem cuidados e não "serem compreensíveis com as falhas da organização". Em setores onde a margem para o erro é muito estreita, estas questões são ainda mais evidentes:

"Em pacientes graves afetados por doenças infectocontagiosas, os cuidados complexos exigem tempo e atenção, e existe muita pressão. Em termos de cuidado dá para realizar, passamos do nosso horário, mas na medicação não se pode errar, a dose é precisa, não se pode errar na quantidade, doses diferentes de paciente para paciente, tem que respeitar o horário, o que é humanamente impossível".

Apesar das dificuldades, relatam que buscam zelar pelo que estão fazendo, há procedimentos que exigem muita atenção e cuidado, não podem, não querem perder uma veia puncionada.

Há muita queixa também com relação às condições de trabalho. Questionam certas prescrições das tarefas utilizando o saber adquirido, e apontam contradições que, no seu entender, colocam em risco a vida dos pacientes. Por exemplo, elas consideram um absurdo a necessidade de passar de uma área contaminada para um setor que exige a mais absoluta higiene sem as devidas condições técnicas e organizacionais (tempo) para a uma higienização e paramentação adequadas.

As condições materiais são também criticadas. Gostariam que o hospital oferecesse condições para que pudessem desempenhar suas funções dentro dos padrões que acreditam ser de qualidade. Os equipamentos não são mantidos adequadamente, faltam equipamentos novos, prejudicando a realização de determinados procedimentos. Além da penúria com relação a equipamentos com maior tecnologia agregada, elas referem-se aos problemas de falta de roupa, fato que constantemente cria problemas na relação com os pacientes, inclusive nos casos de preparação destes para cirurgias.

Diante destes problemas, as auxiliares acreditam que o seu trabalho não é desenvolvido com a qualidade que desejariam. Sentem-se cansadas e freqüentemente acham que trabalham no limite da sua capacidade física e emocional: “...quem sai perdendo é o paciente." Referem que se sentem impotentes, que parece que fingem que conseguem atender a todos, pois acreditam que, em muitos casos, seria necessário se dedicar mais, ficar mais ao lado das pessoas. Emocionam-se quando falam dos erros, quando não dá para "segurar uma morte", se sentem sozinhas "nesta luta". Apesar de
São pressionadas pelo tempo e pelos próprios pacientes. Sentem-se constantemente ameaçadas, pois as falhas são perceptíveis facilmente e muitos pacientes "delatam" os problemas para as chefias.

Referem que há falta de entendimento com a hierarquia e com os médicos, não há espaço para externar suas opiniões, discutir os problemas, construir soluções. Seria uma estrutura organizacional de mando e subordinação, sem espaço para contestação. As ordens que não podem ser cumpridas por questões de tempo e de falta de material são geradoras de ansiedade. A falta de diálogo faz com que se sintam como "robôs" cumprindo ordens. Além disso, reclamam da falta de união, pois acreditam que se houvesse mais solidariedade teriam maior possibilidade para negociar. Sentem-se muito incomodadas quando a chefia faz comparações com outros colegas e outros setores. Acham que todos são pressionados e que são o elo mais fraco da cadeia. A submissão é, segundo elas, bem vista pela hierarquia. A contestação é vista como rebeldia, como falta de vontade de trabalhar. Falam em humilhação quando broncas são dadas na frente de colegas, de médicos, de pacientes. O mesmo acontece quando plantonistas reclamam ao serem acordados, a situação ainda piora quando estes acreditam que o caso não seria urgente.

"Como saber, paciente não marca hora para passar mal"

O sentimento de inutilidade aparece quando relatam que alguém está mal e que vai morrer, mas ninguém acredita nelas. Além do mais, os outros podem jogar a 
responsabilidade nelas, um erro de procedimento, não fez na hora certa, mas elas não teriam em quem descarregar a culpa.

Há vários sinais que indicam um grau alto de ansiedade devido ao trabalho: As brigas têm se tornado mais freqüentes, é comum alguém "descarregar em cima do outro". Pacientes costumam falar mal delas e de seus cuidados, se sentem desrespeitadas e sob constante pressão, muitas reclamações são levadas a sua chefia, se sentem injustiçadas. Há casos extremos, como por exemplo, ao tentar salvar a vida de um paciente, uma delas foi acusada por familiares de pacientes de ter criado o problema, se sentem desnorteadas sobre o que e quando fazer. Elas são a primeira linha de contato, é com elas que as "coisas" acontecem.

Referem ainda que, além de todas estas fontes de sofrimento, as relações com os pares são muito problemáticas. Consideram-se pouco unidas, que uma não colabora com o trabalho da outra, que muitas buscam vantagens e privilégios ao fazerem favores para a chefia. Relatam casos de crise de choro por causa do comportamento de um colega. Por outro lado, mostram que há espaço e sinais claros de solidariedade, como trocas de plantão, cobertura de faltas e cooperação em situações mais críticas. Relatam, entretanto, que isto tem diminuído, que todas estão sobrecarregadas. $\mathrm{O}$ isolamento e a falta de espaço e tempo definido para discutir os problemas são considerados como uma ameaça crescente. Não há onde e com quem desabafar, debater, aprender mais. Relatam que não há nem tempo hábil para as passagens de plantão. Um exemplo ilustrativo está nesta fala:

"Temos que fazer o debate interno, há paciente que não está sendo atendido. Se não falarmos vão sempre achar que estamos dando conta, que tudo está andando bem"

Esta ameaça crescente, se expressa no afastamento de colegas e amigas por adoecimento. Pouco se fala a respeito, há um silêncio, uma espécie de defesa coletiva. Há casos de afastamento por descompensação psiquiátrica, mas um véu de silêncio encobre o debate. Todas têm que estar em condições de dar conta do recado.

Apesar de todos os problemas apontados, há muitos aspectos que relatam serem positivos, principalmente porque gostam do que fazem, pois no fundo, considerando-se todas as adversidades e a aparente contradição do discurso, sentem-se úteis e fazendo o melhor que podem, mesmo não havendo sinais claros de reconhecimento, sabem que estão fazendo um trabalho importante e que isso ajuda a viver os percalços da profissão.

\section{Ser auxiliar de enfermagem}

Após a apresentação geral dos resultados, serão apresentados neste item alguns temas do documento final entregue pelos pesquisadores/facilitadores, considerado pelo grupo como uma espécie de síntese do seu trabalhar.

O ser do(a) auxiliar de enfermagem aparece como profissional do auxílio, da ajuda. Nesse sentido, deveria bastar o cumprimento de procedimentos consagrados para o desempenho de suas tarefas. No entanto, o dia-a-dia desta profissão no hospital mostra a sua complexidade latente.

Este ser se revela como uma espécie de guardião da instituição, pois é o último elo na cadeia de cuidados e atendimento dos pacientes. Qualquer erro que eventualmente venha a ocorrer dentro desta cadeia - professores, residentes, internos, enfermeiras e outros auxiliares pode vir a ter conseqüências graves se não for detectado por ele.

Este ser é um guardião alerta e zeloso e, ao mesmo tempo, dar conta das múltiplas tarefas que lhe são exigidas é difícil, senão contraditório. A demanda é enorme e variável. Isto significa, por exemplo, nunca saber quanto vai se trabalhar naquele dia ou naquela noite, não saber se vai enfrentar problemas com equipamentos, se vai haver interferências de superiores hierárquicos e médicos que dificultem os atendimentos dos pacientes. Como ser atento e vigilante e, ao mesmo tempo, cuidadoso neste contexto? Exige-se uma grande capacidade de adaptação e criação de estratégias operacionais para responder constantemente a este duplo desafio.

\section{criação de um espaço público, no sentido de Arendt (1981), dentro do ambiente de uma empresa, ou entre profissionais de uma determinada categoria abre a perspectiva de trocas e de questionamentos que não se realizavam antes.}

O que se observa então é um constante desvio, "derrapagem", deriva do eixo de sua tarefa. O seu papel se restringiria à aplicação dos procedimentos técnicos, mas uma escuta mais acurada traz à tona uma série de exigências implícitas no seu "que-fazer" de auxiliar: por exemplo, a produção de um saber em função da necessidade de compreender o que se passa com o paciente ao manipular seu corpo. É necessário aprender a escutá-lo, entendê-lo e compreendê-lo em sua singularidade e em seu sofrimento, não se esquecendo que este outro pode ser desde um bebê até uma pessoa idosa. 
Pergunta-se então: como lidar com esta variedade? Como lidar com esta diversidade de corpos, doenças e emoções? Não basta a aplicação fria das técnicas de assistência. Trata-se de um trabalho em que o contato humano é essencial e requer psicologia, sensibilidade, desprendimento tanto com relação a uma pessoa que está melhorando e se recuperando como àquela que está piorando e morrendo. Vive-se, neste último caso, as limitações de seu saber técnico que não possibilita traduzir cientificamente o seu saber prático, o seu saber que vem desse contato que mostra, por exemplo, que tal paciente vai morrer contra todas as previsões dos supervisores e médicos.

Infelizmente, não se reconhece a sua real competência profissional, pois isso implicaria que os outros agentes profissionais deveriam percebessem a existência deste saber prático construído através da experiência. Que o seu saber não se limita à aprendizagem formal das técnicas, mas que englobaria este outro conhecimento. atendidos como acreditam que deveriam ser, e o que é pior, no limite, vivenciar o morrer de vários pacientes que no entender deles não deveriam morrer.

Uma outra dimensão do ser auxiliar é estar sempre disponível. Uma disponibilidade que não tem limite é uma disponibilidade que desfigura a identidade.

Estar disponível é também não ter limites. Precisa dar conta, tapar buraco, fingir que dá conta, trabalhar quando se sente ou está doente, fazer horas extraordinárias, cobrir diferentes setores do hospital. O que é possível fazer? Será que não há limite? Ser auxiliar é se sentir estrangulada pelo trabalho.

Ser auxiliar é se sentir dentro de um coletivo de trabalho reduzido, onde há poucos para realizar tanto trabalho.

Resistir é também aceitar, é se submeter. O papel da aceitação, da submissão ainda é valorizado, é como se sempre tivessem aprendido este papel, a ficarem o tempo todo caladas, não dizerem e fazerem. A submissão é vista como um complemento do medo, da ameaça de punição, do medo de ser excluída e de um sentimento que as coisas nunca vão mudar, pois a experiência do ser auxiliar mostra que a corda arrebenta do lado mais fraco. Cada um exige de um jeito, os supervisores, os médicos, os pacientes, cada um quer de um jeito e no seu tempo.

Ser auxiliar é tentar atender a todas essas exigências técnicas e humanas. Todos querem e precisam resolver suas questões. Os pacientes e seus familiares mostram-se muito ansiosos em determinadas situa-
A sensação que se tem então é a de que a(o) auxiliar é um não-ser. Um ser vazio de identidade dada a falta de reconhecimento daquilo que o constitui como auxiliar. Neste hospital, em particular, corre-se o risco de, ao passar dos anos, se transformar numa "mobília" ou "fazer parte do acervo" da universidade. Peça desprovida de qualquer valor próprio.

A saída é fingir: fingir para não mostrar a sua real vivência, o seu real sofrimento. Trata-se claramente de estratégias defensivas. Tudo se passa como se os acontecimentos fossem naturais, normais. Alguns escutam, mas não falam, outros vêem, mas não "enxergam" e, num terceiro grupo, não falam sobre o que vêem. Todo esforço é no sentido de dar conta das tarefas, ou pelo menos fazer de conta que dão.

Neste jogo institucional tem-se a impressão que todos perdem. No caso dos(as) auxiliares, aqueles que resistem e lutam contra esta situação são os que mais expressam o sofrimento. Sofrem por não conseguirem atingir os seus objetivos e verem que os pacientes acabam não sendo ções. Às vezes, o convívio com os pacientes e seus familiares chega à ameaça ou à violência franca, caso mais comum entre os pacientes presidiários.

Ser auxiliar de enfermagem é navegar em toda essa realidade, formada de múltiplas facetas e modelada por atores diversos. Buscar respeito e identidade, evitar o erro, lutar contra a discriminação, estão sempre presentes, exigem estratégias de regulação e têm consequiências.

Ser auxiliar é transgredir às vezes regras para atender a algum desejo legítimo de um paciente moribundo.

Ser auxiliar de enfermagem é criar estratégias para se defender do sofrimento: tentar esquecer o que acontece quando sai do trabalho, fazer de conta que não é com ele, que não faz parte da sua alçada, se convencer que o estado do paciente não é grave, se virar - fazer sua parte e fechar os olhos para o resto. Interessante é que cada um cria as suas estratégias, são individuais, não coletivas.

Ser auxiliar de enfermagem é garantir a segurança do sistema de atendimento, é ser testemunha. 


\section{Discussão à guisa de conclusão}

Os trabalhos foram desenvolvidos dentro da perspectiva proposta por Dejours, em que se busca uma escuta clínica do trabalho das pessoas envolvidas visando tornar conscientes as várias nuances da situação, os sentimentos, os receios, as estratégias utilizadas para fazer frente ao sofrimento vivido no trabalho.

A atividade de trabalho das auxiliares de enfermagem do grupo é permeada pela compaixão. Em primeiro lugar, a palavra emoção está sempre presente, permeia o discurso dos componentes do grupo. Não é possível ficar imune ao contato com o sofrimento do outro, com o corpo do outro, com os apelos e pedidos de ajuda. Há uma constante relação dialética entre a construção de defesas individuais e coletivas (Dejours,1997) e a mobilização psíquica em direção à compaixão. Ser auxiliar de enfermagem exige um constante trabalho de perlaboração ${ }^{4}$, um esforço para transformar o tema de sofrimento seu e dos outros em um substrato para a elaboração de uma identificação com o trabalho, um caminho para a realização de si.

Entretanto, a questão afetiva que permeia o trabalho das auxiliares é cheia de ambigüidades, pois a entrega necessária para o outro se faz em detrimento da sua própria saúde. Os equipamentos disponíveis, o ritmo, os horários de trabalho e o próprio estado dos pacientes são fatores de constrangimento de tal ordem que a doença profissional torna-se presente. Muitas vezes, estes problemas físicos são mantidos invisíveis, até que cheguem a um nível insuportável. Já o sofrimento psíquico é visto como uma espécie de tabu e, mesmo os processos de descompensação sendo escondidos ao máximo, paira no ar um certo fantasma, uma necessidade de se manter dentro da normalidade.

Outro problema evidente está ligado à violência. Vários são os relatos de casos de pacientes, acompanhantes, que partiram para a agressão. No caso específico há ainda os casos de pacientes internados que estão sob custódia da justiça ou da polícia que, em muitos casos, servem para aumentar ainda mais o risco.

Este trabalho espremido entre os mais diferentes tipos de pacientes, sob a égide de profissionais de nível superior, sob constante demanda técnica e afetiva, é quase invisível, não tem uma identidade profissional própria, desaparece no meio do processo de atendimento. O reconhecimento de utilidade feito pelos níveis hierárquicos superiores pauta-se pela ambigüidade, uma vez que este tipo de trabalho não tem um fim, não pode ter um procedimento padrão. Já entre colegas podem ser criadas relações de solidariedade, de cumplicidade. Entretanto, o que é muito relatado, são os problemas de competição, de disputa, potencializados por uma organização de trabalho que não favorece a cooperação. No mais das vezes, cada um tem que dar conta do recado, pois o absenteísmo tem impacto sobre a quantidade de pessoas disponíveis e o quadro de funcionários não é suficiente para dar conta. A sensação de que o trabalho, o serviço prestado poderia ser melhor é um outro fantasma que paira. Apesar de não ser responsabilidade deles, a presença constante da morte, não apenas como uma possibilidade, mas como um fato, aumenta esta sensação de que algo mais poderia ser feito. 
façamos uma afirmação: A construção da identidade, no caso estudado, passa pela percepção que elas /eles têm de ser uma espécie de guardiões, isto é, eles/elas seriam o último elo de uma cadeia de assistência ao paciente. Se alguma falha ou erro passar por aí, o resultado pode ser catastrófico.

\section{Artigo recebido em 27/05/2004 Aprovado para publicação em 02/02/2005}

\begin{abstract}
Notas
1. Dejours usa o termo tricherie no original. Gostaríamos de alertar que ele utiliza-o num sentido positivo, não há um uso com uma conotação pejorativa e assim deve ser entendido pelo leitor
\end{abstract}

2. Na exposição do trabalho em geral do auxiliar de enfermagem, utilizaremos o substantivo masculino.
3. A partir deste momento falaremos no feminino, ou seja, as auxiliares de enfermagem. Trabalhamos com 14 auxiliares mulheres e somente um auxiliar e dada esta predominância optamos por falar no feminino.
4. Trata-se de um conceito psicanalítico: É uma espécie de trabalho psíquico que permite ao indivíduo aceitar certos elementos reprimidos (inconscientes) e se libertar da influência dos mecanismos repetitivos. (LAPLANCHE e PONTALIS, 1976).

\section{- Bibliografia}

ARENDT, H. A condição humana. São Paulo: EDUSP, 1981.

BILLIARD, I. Les conditions historiques et sociales d'apparition de la psychopathologie du travail en Frande (1920-1952). In Les Histoires de la Psychologie du Travail, 2. ed. Toulouse: OCATARÈS Éditions, 1999.

CLOT, Y. Le Travail sans l'Homme? Pour une psychologie des milieux de travail et de vie. Paris: Éditions la Découverte, 1995.

CLOT, Y. La fonction psychologique $d u$ travail. Paris: Presses Universitaires de France, 1999.

CRU, Damien. Les règles du métier. In Plaisir et Souffrance dans le Travail. Séminaire Interdisciplinaire $d u$ Travail. Paris: Centre National de la Recherche Scientifique, 1987.
DEJOURS, Christophe. Plaisir et Souffrance dans le Travail: l'approche par la Psychopathologie du Travail. In: Plaisir et Souffrance dans le Travail. Séminaire Interdisciplinaire de Psychopathologie du Travail. Paris: Centre National de la Recherche Scientifique, 1987.

DEJOURS, Christophe. Intelligence pratique et sagesse pratique: deux dimentions méconnue du travail réel. In: Comprendre le Travail - Première partie, n. 116, 1993-3 (sous la direction de Guy Jobert).

DEJOURS, Christophe. Analyse psychodynamique des situations de travail et sociologie du langage. In: Paroles au Travail, L'Harmattan (sous la direction de Josiane Boutet), Collection Langage \& Travail, 1995.

DEJOURS, Christophe. O Fator Humano. Rio de Janeiro: Editora Fundação Getúlio Vargas, 1997.
DEJOURS, Christophe. Conferências Brasileiras. São Paulo: Edições FUNDAP; EAESP/FGV, 1999.

DEJOURS, Christophe. Psychologie Clinique du Travail et Tradition Compréhensive. In CLOT, Y. Les Histoires de la Psychologie du Travail. Approche pluri-disciplinaire. 2. ed Toulouse: OCTARÈS Éditions, 1999.

DEJOURS, Christophe. Travail, usure mentale. Paris: Bayard Éditions, 2000.

GUÉRIN, F. et al. Compreender o Trabalho para Transforma-lo. A Prática da Ergonomia. São Paulo: Editora Edgard Blücher Ltda., 2001.

HABERMAS, J. Théorie de l'Agir Communicationnel. Paris: Fayard, 1987, 2 vols.
LAPLANCHE, J. e PONTALIS, J. Vocabulário de Psicanálise. 3. ed., Lisboa: Moraes Editores, 1976.

MOLINIER, P. Psychodynamique du travail et identité sexuelle. Paris, Tese de doutorado, Laboratoire de Psychologie du Travail, Conservatoire National des Arts et Métiers, 1995.

MOLINIER, P. Gestion hospitalière et souffrance éthique des personnels hospitaliers. Palestra proferida nas Escola Politécnica da USP, mimeo, 2003.

TONNEAU, D. et al. L'organisation du travail dans les services de soin, Lyon: ANACT, 1996.

VÉZINA, M. Les fondements théoriques de la psychodynamique du travail. In: Le Travail et ses Malentendus: Psychodynamique du travail et gestion. Les Presses de l'Université Laval et Octares Éditions, Toulouse, 2000. 